\title{
Dual Activity Patterns of Fast Pyramidal Tract Cells and Their Family Neurones during EEG Arousal in the Cat
}

\author{
Kazuhisa EzUre and Tomokazu OsHImA \\ Department of Neurobiology, Tokyo Metropolitan Institute for \\ Neurosciences, Musashidai, Fuchu, Tokyo, 183 Japan*
}

\begin{abstract}
Intracellular activities of fast pyramidal tract (PT) cells and their family neurones were investigated during the EEG arousal of various degrees in terms of (1) the strength of natural or midbrain reticular stimuli, (2) the length of aroused EEG and (3) the extent of stage shift from EEG synchronization to desynchronization. 2. These cells showed a response pattern of either disfacilitation (DF), disfacilitation followed by excitation $(\mathrm{DF}+\mathrm{E})$ or excitation $(\mathrm{E})$. DF and $\mathrm{E}$ components in these responses were respectively quantified with their amplitude and incidence, and their relations to the above-listed intensity parameters of EEG arousal were examined. 3. The threshold of eliciting DF response was lower than that for $\mathrm{E}$ response to natural and reticular stimuli. On intensifying the parameters of EEG arousal, accompanying increases were observed in $E$ response but not in DF response. Rather, DF response was often masked by E response on application of relatively intense stimuli, or was decreased in a reciprocal manner to the increase of $E$ response in accordance with the degree of EEG arousal. 4. It is postulated that the phasic and tonic phases of EEG arousal manifested, respectively, as the initial DF and late E responses bear different functions, the former representing the cerebral state of a general set on receipt of a novel stimulus, and the latter involving the state of actively responding to the stimulus by encoding its intensity.
\end{abstract}

The initial phasic and late tonic phases of EEG arousal have been discriminated according to the differences in susceptibility to habituation (SHARPLESS and JASPER, 1956), in the amplitude of the cortical evoked potentials (WALSH and CoRdEAU, 1965; Allison and GoFF, 1968; Courtois and CoRdeAu, 1969) or in the firing rate of cortical neurones (Steriade, 1970; Steriade et al., 1974a, b; Steriade and HoBSON, 1976). In the motor area of the cat cerebral cortex, fast pyramidal tract (PT) cells and some non-PT cells play a part of the index differentiating between these two phases of EEG arousal by displaying a dichotomic pattern consisting

Received for publication March 19, 1981

* Reprint request to Dr. T. Oshima

江連和久, 大島知一 
of an initial disfacilitation (DF) and a late excitation (E) (INUBUSH et al., 1978b). These cells, which are named DF cells, exhibit either DF only or DF followed by $\mathrm{E}(\mathrm{DF}+\mathrm{E})$, and these different response patterns are perhaps dependent on the physiological intensity of EEG arousal (EzURE et al., 1980). It is thus assumed that the phasic and tonic phases of EEG arousal indicate different functional states, the former representing an initial stage of the orienting reflex such as an interruption of ongoing movements, and the latter corresponding to an active investigatory response (PAVlov, 1927; FANGEL and KAADA, 1960; SoKolov, 1963; Floru, 1975; Steriade and Hobson, 1976; INUBushi et al., 1978b).

A series of microelectrode studies has been undertaken to investigate further the neuronal aspect of the above assumption. For this purpose, the dual activities of motor cortical neurones were analyzed in more detail on their patterns and properties. Fast PT cells provide the most appropriate cell sample to pick up first for this analysis being the only index so far obtained to differentiate between the phasic and tonic EEG arousal. This paper describes an analysis of the activities of fast PT cells as well as of some non-PT cells as the family neurones of the former during EEG arousal at various intensities. The criteria for selecting these non-PT cells were the same properties as those of fast PT cells in (1) the response pattern of $\mathrm{DF}+\mathrm{E}$ and (2) the depths of location ranging between 800 and $1,600 \mu \mathrm{m}$ from the cortical surface. As parameters that indicate the intensity of arousal, we have adopted the strength of natural or midbrain reticular stimuli employed to induce EEG arousal, the length of aroused EEG and the extent of stage shift from EEG synchronization to desynchronization. Characteristics of the phasic and tonic phases of EEG arousal will be summarized in this paper on the basis of DF cell responses. Studies will then follow to explore the behaviour of the cortical neurones other than DF cells, and to reveal the neuronal integration achieved in the two phases of EEG arousal by contribution of the cortical neurones of all species (EzURE and Oshima, 1981a, b).

\section{METHODS}

The present experiments are the continuation of a previous study on EEG arousal in cat motor cortex, with the same experimental procedure and arrangement of stimulating and recording electrodes (INUBUSHI et al., 1978a, b). The electrocorticogram of the precruciate cortex (motor EEG) was always monitored, and recordings of the visual EEG and the hippocampal activity were also made in some experiments. Stimulation of the midbrain reticular formation was used, but not always because many episodes of EEG arousal could be elicited spontaneously or by natural stimuli in some experiments.

The activities of motor cortical neurones were intracellularly recorded during EEG arousal. The midpontine pretrigeminal or encéphale isolé brain preparation of the cat was maintained in a dimly lit and sound-attenuated shielded room. 
The episodes of EEG arousal so far analyzed in our previous study were only spontaneous ones occurring without particular natural stimuli or those induced by the weakest, juxta-threshold stimulation of the reticular formation. When the reticular stimulation failed to mimick the spontaneous EEG arousal in the responses of a recorded neurone, such a trial was excluded from previous analysis (INUBUSHI et al., 1978a). However, trials of this sort will be taken into consideration in this and the following papers (EzURE and OsHima, 1981a, b) with many other new trials in which attempts were made to induce EEG arousal by both natural (visual and acoustic) and reticular stimuli with different intensities.

While recording the intracellular potentials of a neurone through a $\mathrm{KCH}_{3} \mathrm{SO}_{4}$ filled glass microelectrode from the precruciate cortex (area $4 \gamma$ ), EEG arousal occurred spontaneously, or was induced by natural or reticular stimulation. The response type of cells was identified by means of measurements of the membrane potential and impedance and of the incidence of spontaneous unitary postsynaptic potentials, as described previously (INUBUSHI et al., 1978b). Hyperpolarizing pulses were routinely injected every 1 or $1.5 \mathrm{sec}$ or so, to observe two levels of membrane potential (Fig. 1A, D). The hyperpolarized level was often omitted from recorded traces to see potential changes with high amplifications (Figs. 1B-C, 3, 4). PT cells were identified by stimulating the cerebral peduncle (OsHIMA, 1969; INUBUSH et al., 1978a). The reticular stimulation was made by pulses of $0.1 \mathrm{msec}$ in width, $20-300 \mu \mathrm{A}$ in intensity, repeated with a frequency of 100,200 or $300 \mathrm{~Hz}$ for a total period of $1-15 \mathrm{sec}$. A repetitive flash of light $(5-20 \mathrm{~Hz})$ was derived from a photic stimulator (Digitimer, Model 3182) and applied through a tube (1.5 ins. in diameter) placed $30-90 \mathrm{~cm}$ in front of the head of a cat. For acoustic stimulation, pip sound was derived through a conventional loud-speaker driven by pulses of adjustable voltages and frequencies $(600-1,000 \mathrm{~Hz})$. The most effective natural stimuli were noises or voice created by the experimenters, e.g., opening the door of the shielded room, whistling and calling. The EEG arousal reaction was habituated quickly to flash or pip sound stimulation, but was maintained close to the experimenter's voice ( $c f$. Fig. 1C).

The ink-writing displays illustrated in Figs. 1, 3 and 4 were reconstructed from the records stored on magnetic tape with a data recorder (Sony DFR-2915). The read-out speed was the same as during the experiment, and the frequency characteristic of a pen recorder (Mingograf 800) was set in the range from d.c. to $650 \mathrm{~Hz}$, unless stated ( $c f$. legend of Fig. 1).

The depths at which intracellular potentials were recorded were measured for respective neurones from the cortical surface by reading on an electronic micromanipulator (Narishige ME-71) during the experiment, and the vertical direction of microelectrode tracking was verified histologically after the experiment (INUBUSHI et al., 1978a). 


\section{RESULTS}

\section{Sampling of neurones}

Thirty-four DF neurones including 16 fast PT cells were selected for analysis with the criterion that they exhibited both the DF and DF $+E$ responses. This criterion was adopted to exclude some DF cells which were examined only under the weakest EEG arousal as described previously (INUBUSHI et al., 1978a).

Ten of the 34 neurones were sampled from 7 pretrigeminal cats and the remaining 24 were from 18 encéphale isolé cats. Seven fast PT cells were included in the former group of 10 cells, and 9 fast PT cells belonged to the latter group of 24 cells. All of these 34 cells were located at depths of $800-1,600 \mu \mathrm{m}$ from the cortical surface. These cells were subjected to EEG arousal at least twice or up to 58 times. The total number of episodes of EEG arousal tested was 447, and the mean per cell was 13 with the standard deviation of \pm 14 .

\section{Response patterns}

The response patterns of sampled cells were of different combinations of DF and $\mathrm{E}$ responses. Figure 1 illustrates various patterns of activity recorded from a non-PT DF cell during the EEG arousal. The EEG was aroused mainly by acoustic stimuli in a variety of experimental situations.

In Fig. 1A, a relatively weak pip sound is applied (1), and the motor EEG (2) is shifted from synchronization (slow waves and spindle bursts) to desynchronization (low voltage fast activity) at a point marked by a vertical arrow a. Correspondingly, a small membrane hyperpolarization is induced together with an increase of the deflection produced by passing pulse currents, that is, of the membrane impedance (horizontal bar with arrowheads $c$ in A3). Close inspection of these changes can be made, as illustrated in Fig. 2A, by quantifying the membrane potentials at resting level $\left(V_{\mathrm{R}}\right)$ and at a subsequent hyperpolarized level $\left(V_{\mathrm{H}}\right)$ during passage of a current step $(I)$. The effective membrane resistance $\left(R_{\mathrm{M}}\right)$ is obtained by dividing the difference $(\Delta V)$ between $V_{\mathrm{R}}$ and $V_{\mathrm{H}}$ by the applied current $(I)$. In Fig. 2B from top to bottom the values of $V_{\mathrm{R}}, V_{\mathrm{H}}$ and $R_{\mathrm{M}}$ are plotted for the episode of Fig. 1A, as the function of time measured from the onset of EEG arousal at 0 (see bottom scale). For $V_{\mathrm{R}}$ and $V_{\mathrm{H}} 8$ consecutive values are averaged to plot the means (open circles) and standard deviations (vertical solid bars). $\quad R_{\mathrm{M}}$ is plotted with filled circles for each current step. For the initial phase of EEG arousal marked by a horizontal bar $\mathrm{c}$ on the top of Fig. 2B (the period corresponding to that indicated by the bar c in Fig. 1A) both $V_{R}$ and $V_{\mathrm{H}}$ are hyperpolarized and stabilized, as indicated by the downward shift of potential plots and standard deviations smaller than those during the preceding period. $R_{\mathrm{M}}$ fluctuates considerably before the EEG arousal. It is lowered transiently in phase with the spindle burst waves in EEG, as indicated by small arrows in $R_{\mathrm{M}}$ plots. In spite of this fluctuation, $R_{\mathrm{M}}$ is increased significantly on the EEG arousal for the period marked by the arrow c. Thus, these changes of membrane 


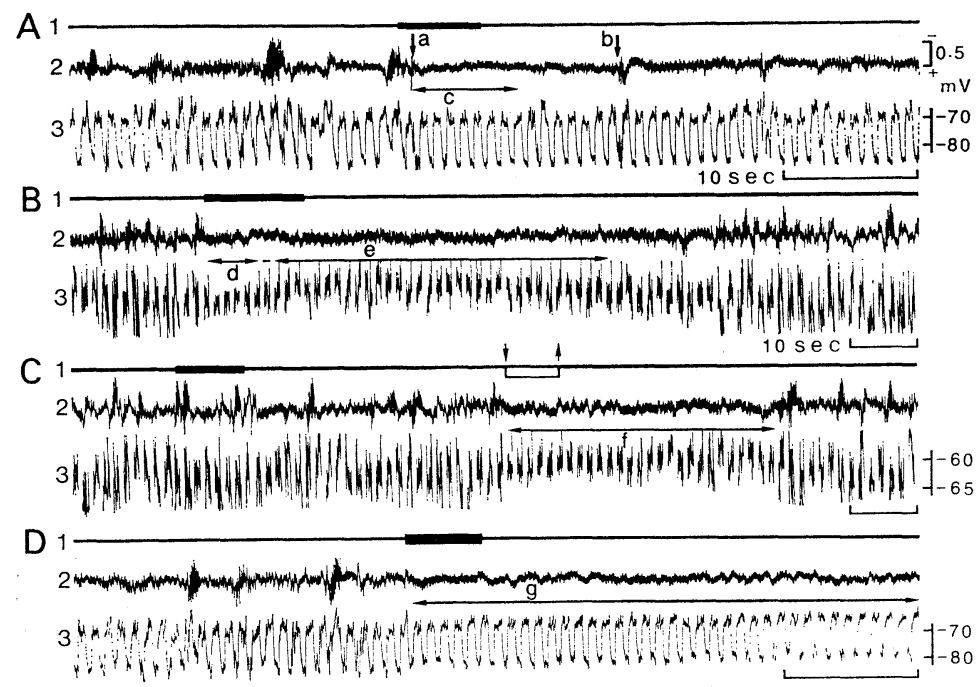

Fig. 1. Different intracellular responses of a DF cell to EEG arousal. Non-PT cell (depth, $1,190 \mu \mathrm{m})$. Encéphale isolé cat. In A, pip sound is given as marked by thick solid bar in (1) for $6 \mathrm{sec}$ with frequency of $600 \mathrm{~Hz}$ and amplitude of arbitrary voltage unit $(1.0 \mathrm{~V})$. In motor EEG (2) low voltage fast activity starts at a point marked by a vertical arrow $a$, and the first sign of recovery from arousal pattern is indicated by an arrow $b$ with appearance of a small spindle burst wave. Membrane potential (3) shows two levels produced by applying hyperpolarizing current pulses $(-2.0 \mathrm{nA}$ for $400 \mathrm{msec})$ every second. DF response is demonstrated mainly during a period indicated by a horizontal bar with arrowheads c. Records in B and $\mathrm{C}$ are a continuous trace displayed with high amplification, during which pip tone is applied twice (1.4 V, solid bars in 1) and an experimenter's noise is given once (hollow bar with arrows). DF $+\mathrm{E}$ (B3, bars $\mathrm{d}$ and $\mathrm{e})$ and exclusive $\mathrm{E}$ responses ( $\mathrm{C} 3$, bar $\mathrm{f}$ ) are shown with high amplification that discards the potential levels hyperpolarized by current pulses applied every $1.5 \mathrm{sec}$. $\mathrm{D}$ illustrates $\mathrm{E}$ response (bar $\mathrm{g}$ ) to intensified pip (1.8 V). Voltage scale of $0.5 \mathrm{mV}$ applies to EEG records in A-D. Levels of membrane potential in $\mathrm{mV}$ and time scales of $10 \mathrm{sec}$ are given respectively in A-D. Membrane potentials (3) in this particular figure are displayed through an electrical low pass filter with a cut-off frequency of $3.2 \mathrm{~Hz}$. Spikes are off the records.

hyperpolarization and the $R_{\mathrm{M}}$ increase or the conductance decrease indicate that the response is DF in this episode of EEG arousal. Tonic maintenance of EEG desynchronization is interrupted by appearance of a small spindle burst activity at a point marked by a vertical arrow $\mathrm{b}$ in Fig. $1 \mathrm{~A}$, and the membrane hyperpolarization and the $R_{\mathrm{M}}$ increase tends to recover then with some fluctuation (Fig. 2B).

A slightly louder and longer pip applied in Fig. 1B (1) causes a transient DF (bar $\mathrm{d}$ in B3) followed by an E response (bar e), the latter consisting of depolarization accompanying a decrease of the membrane impedance $\left(R_{\mathrm{M}}\right.$, not illustrated but see comparable changes in the trial of D), during a longer-lasting episode of 

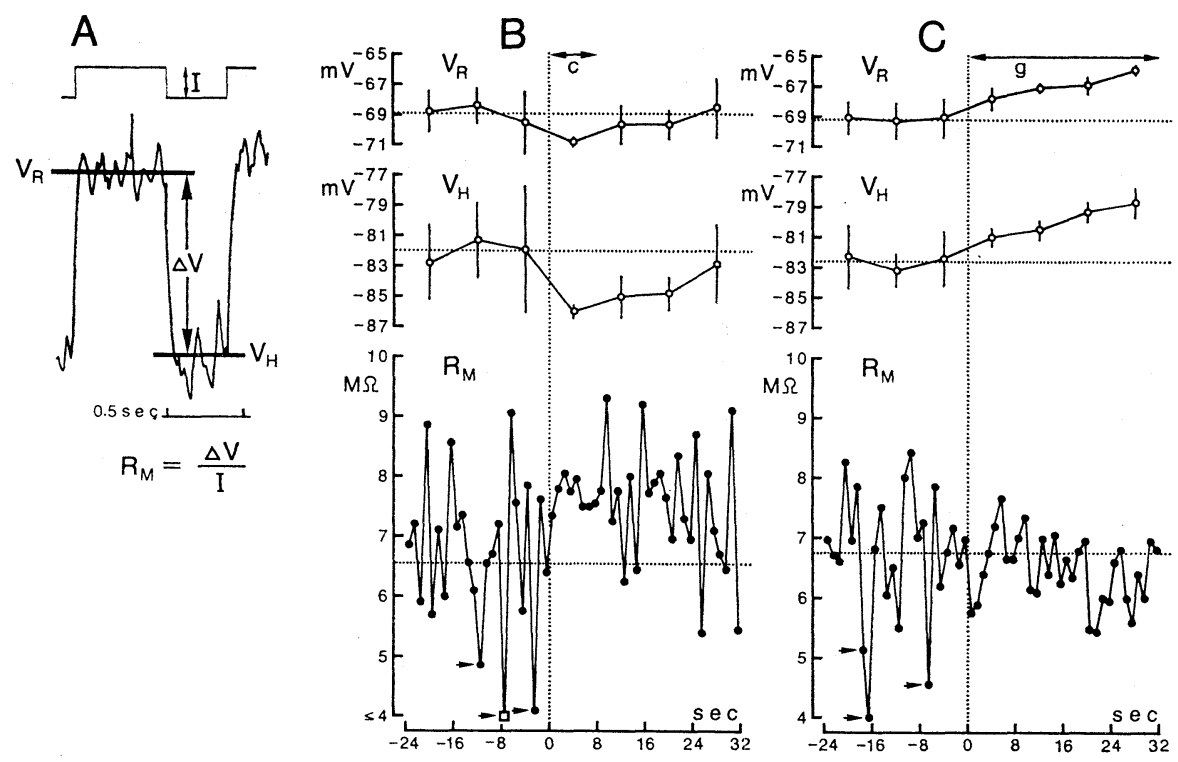

Fig. 2. Membrane potentials and impedance during DF and E responses. A illustrates with schematic representation of current (upper trace) and potential records (lower trace) how to measure average membrane potentials at a resting level $\left(V_{R}\right)$ and the following hyperpolarized level $\left(V_{\mathrm{H}}\right)$ during current injection $(I)$. The difference $(\Delta V)$ between $V_{\mathrm{R}}$ and $V_{\mathrm{H}}$ divided by current $(I)$ is $R_{\mathrm{M}}$. $V_{\mathrm{R}}, V_{\mathrm{H}}$, and $R_{\mathrm{M}}$ are plotted in $\mathrm{B}$ for the episode of DF response illustrated in Fig. 1A and in $C$ for $E$ response of Fig. 1D. Horizontal bars with arrowheads $\mathrm{c}$ and $\mathrm{g}$ correspond to bar $\mathrm{c}$ in Fig. 1A and bar $\mathrm{g}$ in Fig. 1D, respectively. In $\mathrm{B}$ and $\mathrm{C}$, horizontal dotted lines indicate mean control levels of respective parameters before episodes of EEG arousal, and vertical dotted lines mark onsets of respective arousal episodes. $R_{\mathrm{M}}$ plotted with an open square in $\mathrm{B}$ is exceptionally small $(1.5 \mathrm{M} \Omega$ ), and plotted as less than $4 \mathrm{M} \Omega$ ( $\leqq 4$ on the ordinate). Further explanation in text.

EEG arousal (B2). When the pip is further intensified (D1), an exclusively E response with decreases of the membrane impedance (bar $g$ in D3) is induced and maintained for a long time, outlasting the period of record in D. In Fig. 2C this exclusive $\mathrm{E}$ response is proved to occur by demonstrating both the slowly rising depolarization in plottings of $V_{\mathrm{R}}$ and $V_{\mathrm{H}}$ and the correspondingly decreasing $R_{\mathrm{M}}$. The change in $R_{\mathrm{M}}$ appears to be very small in this trial because of a fluctuating $R_{\mathrm{M}}$ during the control period before the EEG arousal, particularly during the spindle bursts which involve remarkable $R_{\mathrm{M}}$ decreases as indicated by small arrows in $R_{\mathrm{M}}$ plots in Fig. 2C. However, slowly developing decreases of $R_{\mathrm{M}}$ as well as decreases of its fluctuation are significant in the plotting of this figure.

The observations described above suggest that there are three patterns of cellular responses: (1) DF only, (2) DF followed by $\mathrm{E}(\mathrm{DF}+\mathrm{E})$ and (3) $\mathrm{E}$ only, and that the sequence of $\mathrm{DF}, \mathrm{DF}+\mathrm{E}$ and $\mathrm{E}$ responses is roughly in accordance with the order of physical intensity of stimuli. 
This simple parallelism between the stimulus intensity and the response pattern was not held when the arousal episodes were induced with intervals not sufficiently long to avoid habituation. As illustrated in Fig. 1C, which contains recordings starting immediately in continuation from $B$, the pip sound is repeated (thick solid bar in $\mathrm{C} 1$ ) about $2 \mathrm{~min}$ after the trial in B1 with the same intensity, and it fails to elicit the arousal reaction either in EEG (C2) or in intracellular potentials (C3). The time lag of 2 min would not have been long enough to obviate the strong arousal effects by the preceding pip (B). About $40 \mathrm{sec}$ after this unsuccessful pip trial, an experimenter entered the shielded room calling the cat $(\mathrm{C} 1$, hollow bar with arrows). This stimulation immediately aroused the EEG pattern $(\mathrm{C} 2)$ with a strong E response of the cell (C3, bar f).

Table 1 summarizes the response patterns in DF cells during EEG arousal. The numbers of occurrences of EEG arousal are listed according to the accompanying cellular responses. The majority $(n=85)$ of the 114 episodes in the pretrigeminal cats was induced by reticular stimulation. On the other hand, most of the arousal reactions examined in the encéphale isolé cats were of natural origin, as indicated by a relatively low incidence (32/333) of the reticular trial.

As seen in Table 1, all DF, DF $+\mathrm{E}$ and $\mathrm{E}$ responses were observed in both the pretrigeminal and encéphale isolé cats, regardless of whether they occurred spontaneously or were induced by natural or reticular stimulation. It should further be noted that an exclusive E response could be observed in the present study ( $c f$. Discussion). None of this was taken into consideration in our earlier study, in which we strictly confined the range of intensity for reticular stimulation to near the threshold and care was taken not to disturb the natural origin (INUBUSHI et al., 1978a; EzURE et al., 1980).

\section{Measures of DF and $E$ responses related to stimulus intensity}

Stimulus-response relationship for reticular stimuli. To quantify DF and E responses separately we could measure their maximum amplitude during EEG arousal (see the inset of Fig. 5). The possible relationship between the response amplitude and the stimulus intensity was best examined by applying reticular stimuli

Table 1. Responses in DF cells to EEG arousal.

\begin{tabular}{lccccc}
\hline \multirow{2}{*}{ Preparation } & \multirow{2}{*}{$\begin{array}{c}\text { Number } \\
\text { of } \\
\text { cells }\end{array}$} & \multicolumn{4}{c}{ Number of episodes of EEG arousal with } \\
\cline { 3 - 6 } & DF response & DF+E response & E response & Total \\
\hline Pretrigeminal & $10(7)^{*}$ & $52(25)^{* *}$ & $39(37)$ & $23(23)$ & $114(85)$ \\
Encéphale isolé & $24(9)$ & $172(12)$ & $126(10)$ & $35(10)$ & $333(32)$ \\
Total & $34(16)$ & $224(37)$ & $165(47)$ & $58(33)$ & $447(117)$ \\
\hline
\end{tabular}

* Numbers of cells in parentheses indicate population of fast PT cells.

** Entries in EEG arousal show total numbers of episodes occurring spontaneously and those induced by natural and reticular stimuli. Those of the reticular trials only are indicated in the parentheses. 
to the pretrigeminal preparation under the condition of a well-stabilized EEG pattern (INUBUSH et al., 1978a).

Figure 3 illustrates the effects exerted on motor EEG (2), hippocampal activity (3) and intracellular potentials (4) by the reticular stimuli (1) with different intensities. In $\mathrm{A}$, the stimulus intensity $(24 \mu \mathrm{A})$ is just enough to block some slow waves in the motor EEG (2) and to increase the frequency of hippocampal rhythmic slow activity (RSA). The instantaneous frequency (IF) of RSA is plotted at the bottom below a set of potential records in $\mathrm{A}$, and shows its prompt increase on the reticular stimulation. However, this stimulus is just below the threshold for eliciting DF response (4). With a slightly increased stimulus $(28 \mu \mathrm{A})$ in $\mathrm{B}$, the membrane hyperpolarization by DF response (4) appears clearly for the period marked by a horizontal bar (a). In $C$ and $D$, intensified stimuli (31 and 40
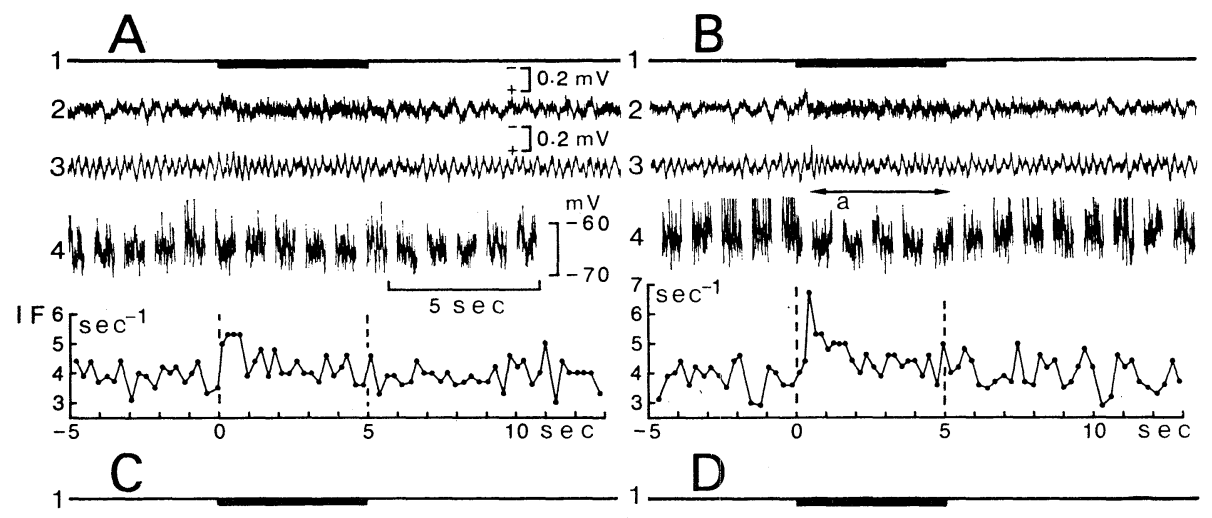

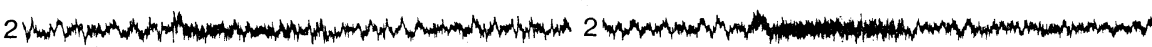

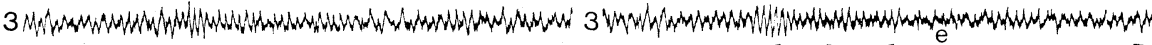
4) Why d
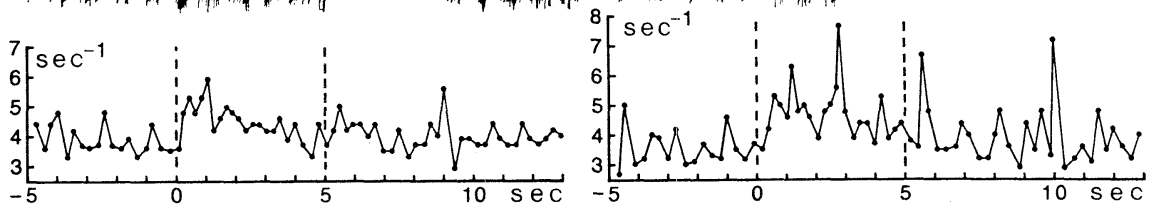

Fig. 3. Effects of reticular stimuli with different intensities in frequency of $100 \mathrm{~Hz}(1)$ on motor EEG (2), hippocampal activity (3) and intracellular potentials (4) of a fast PT cell with a latency of $0.5 \mathrm{msec}$ from cerebral peduncle (depth, 1,300 $\mu \mathrm{m}$ ). Pretrigeminal cat. Horizontal bars with arrowheads in 4 indicate approximate periods of DF $(a, b, d)$ and $E$ responses (c, e). Intracellular records (4) are interrupted by passages of hyperpolarizing pulses for $310 \mathrm{msec}$ every second. Voltage and time calibrations apply to A-D. Mean levels of membrane potential are almost the same (ranging between -63 and $-65 \mathrm{mV}$ ) during control periods of all trials in A-D. Instantaneous frequencies (IF) of hippocampal RSA are measured by hand and plotted below in each set of A-D. 
$\mu \mathrm{A}$, respectively) cause $\mathrm{DF}+\mathrm{E}$ responses (4). The $\mathrm{DF}$ responses in $\mathrm{C}$ and $\mathrm{D}$ marked by bars $\mathrm{b}$ and $\mathrm{d}$ show no significant increases in amplitude compared to the DF response in $\mathrm{B}$. On the other hand, the $\mathrm{E}$ response in $\mathrm{D}$ marked by bar e shows a larger amplitude and longer duration than that in $\mathrm{C}$ marked by bar c. Gradual increases of the stimulus intensity in the trials of A-D are effective not only in increasing E responses, butalso in increasing IF of hippocampal RSA. However, the increases of IF were feeble, and their maximum changes were not in phase with $\mathrm{E}$ responses.

Another example is given in Fig. 4 to show that a reticular-induced DF response (B3, bar b; stimulus intensity, $100 \mu \mathrm{A}$ ) mimicks well that occurring spontaneously (A3, bar a), and that any DF response is masked completely by a strong $\mathrm{E}$ response $(\mathrm{C} 3$, bar $\mathrm{c})$ induced by a stimulus of increased intensity $(170 \mu \mathrm{A})$.

The amplitudes of DF and $E$ responses were measured in three different fast PT cells for the stimulus intensity of a relatively wide range. These values are plotted in Fig. 5 as a function of the stimulus as times of threshold for EEG arousal on the abscissa in a logarithmic scale. Each point represents one trial or the mean of several trials. DF responses in two of these cells (closed triangles and squares) maintain their amplitudes at appreciably constant levels against
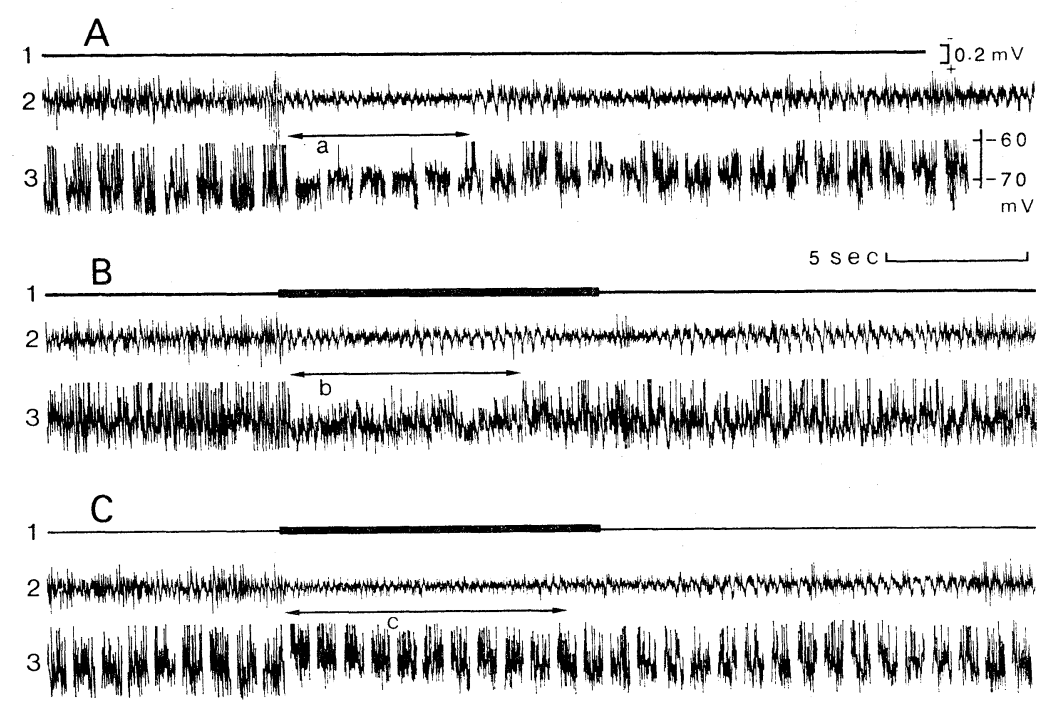

Fig. 4. Comparison of reticular-induced $(B, C)$ with natural EEG arousal (A) in responses of a fast PT cell (depth, 1,500 $\mu \mathrm{m})$. Latency of $0.5 \mathrm{msec}$ from cerebral peduncle. DF ( 3 in A, B marked by bars a and b) and E responses ( 3 in $C$ marked by bar c) are illustrated with motor EEG (2) in a pretrigeminal cat. Intensities of reticular stimuli (1) are 100 (B) and $170 \mu \mathrm{A}(\mathrm{C})$ in $200 \mathrm{~Hz}$. Intracellular records in $\mathrm{A}$ and $\mathrm{C}$ are interrupted by passage of current steps for $200 \mathrm{msec}$ every 1.17 (A) or $0.96 \mathrm{sec}$ (C). Voltage and time calibrations apply to A-C. Mean levels of membrane potential during control periods are the same for trials in $\mathrm{A}-\mathrm{C}$. 
different stimulus intensities, but those in the other cell (closed circles) are completely masked by $\mathrm{E}$ responses except for the case of threshold stimulation. On the other hand, the amplitude of $\mathrm{E}$ responses in all three cells is steadily increased as the stimulus intensity is increased (open symbols).

Response incidence as a measure of response size. Since the maximum amplitudes of DF and E responses could be measured only in several cells under limited conditions, it was desired to adopt another measure of the response size. The incidences of DF and $\mathrm{E}$ responses in a population of cells proved to be a possible index of the response size. Thus, 83 reticular trials in 12 selected cells were lined up according to the stimulus intensity used, and fractionized into subgroups, each of which included 10 trials. In each fraction, the response patterns were classified into DF, DF $+\mathrm{E}$, and $\mathrm{E}$. The incidence of $\mathrm{DF}$ response was counted as the sum of the trials with $\mathrm{DF}$ and $\mathrm{DF}+\mathrm{E}$ patterns, and that of $\mathrm{E}$ response was the sum of the trials of $\mathrm{DF}+\mathrm{E}$ and $\mathrm{E}$ patterns. In Fig 6, these DF and $\mathrm{E}$ incidences are separately plotted as the length of columns on the upward and

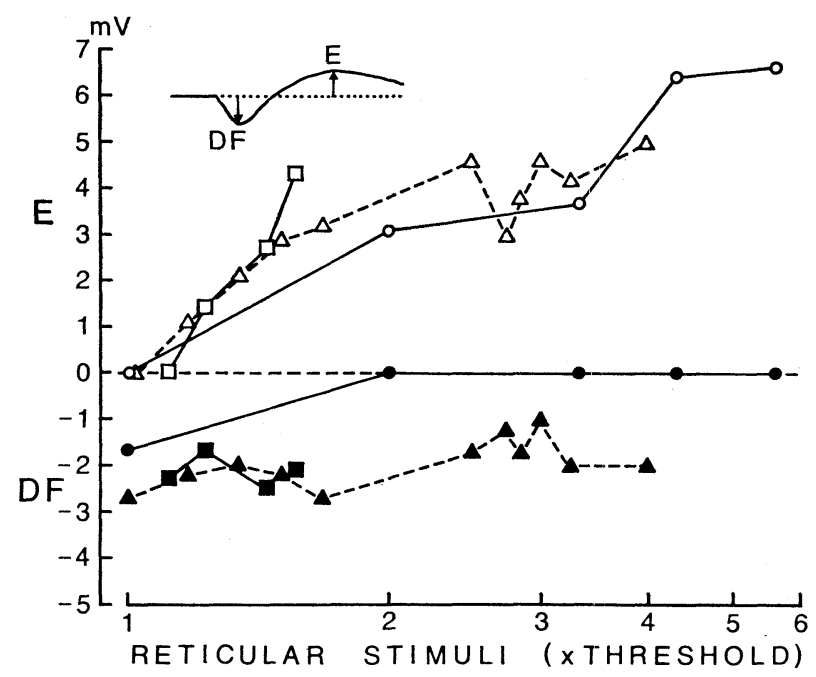

Fig. 5. Stimulus-response relationships in DF and $E$ responses to reticular stimuli. Three fast PT cells in pretrigeminal cats are used. Their latencies from cerebral peduncle are $0.5,0.6$, and $0.65 \mathrm{msec}$, respectively. From a cell No. 1 (depth, $1,410 \mu \mathrm{m}$ ), 16 episodes of EEG arousal are recorded, amplitudes of DF and E responses measured in respective episodes, as illustrated in the inset figure, averaged for the same stimulus intensities and plotted with filled and open circles, respectively, against stimuli as times the threshold for eliciting EEG arousal $(20 \mu \mathrm{A}, 100 \mathrm{~Hz})$. A logarithmic scale is used on abscissae conventionally for spacing in this and the following figures. For a cell No. 2 (depth, $880 \mu \mathrm{m}$ ), 23 episodes are plotted as closed and open triangles for DF and $\mathrm{E}$ responses, respectively, with the same procedure (threshold stimulus, $30 \mu \mathrm{A}$ ). A cell No. 3 (depth, 1,300 $\mu \mathrm{m}$ ) plotted as closed and open squares for DF and E responses, respectively, shows 11 episodes and threshold stimulus of $26 \mu \mathrm{A}$. 


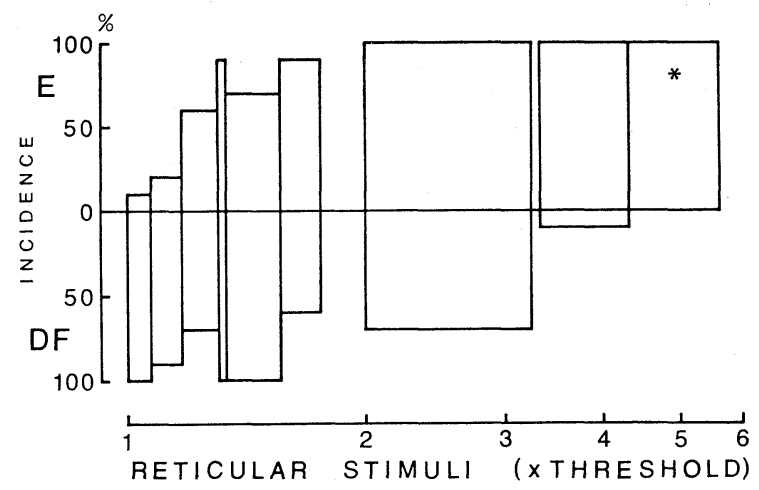

Fig. 6. Relationships between DF or E response incidence and intensity of reticular stimuli. Each column consists of 10 trials except for a column marked by an asterisk with three trials as $100 \%$. See text for further explanation.

downward ordinates against the stimulus intensity with its range as the width of columns on the abscissa. In this figure, DF incidence decreases and E incidence increases as the stimulus intensity is increased. From resemblance to the relations illustrated in Fig. 5, the incidence versus stimulus relations could thus depict the characteristics of the stimulus-response relationships of DF and E responses. In the following sections, the response incidence will be employed for analysis as the response size, whenever necessary so as to generalize the results obtained in a limited number of experiments to the whole population of cells.

\section{Cell responses related to aroused EEG pattern}

Arousal length. In adopting possible intensity parameters from the EEG pattern it is natural to consider first the length of aroused motor EEG, because differentiation of phasic and tonic arousal concerns by nature the length factor. An attempt was made to measure the period between the onset of EEG arousal and the first sign of its recovery often indicated by EEG slow waves or spindles, as marked in Fig. 1A with two vertical arrows, a and b, respectively. This period was termed the arousal length (AL). An actual value of AL in each trial was rounded to the nearest second. It corresponded well with most of the period of cellular responses (Figs. 1, 3, 4).

The fractionized 83 reticular trials were used to examine the relationship between $\mathrm{AL}$ and the stimulus intensity. In the logarithmic plottings of mean ALs and stimulus intensities in Fig. 7 it is shown that AL is approximately proportional to the stimulus intensity, as is referred to by a broken straight line with the exponent of 1 .

$D F$ and $E$ responses versus $A L$ relationship. From the positive correlation between the stimulus intensity and AL it is presumed that the amplitudes of DF and $\mathrm{E}$ responses are related to $\mathrm{AL}$ in a manner similar to the relation with stimulus 


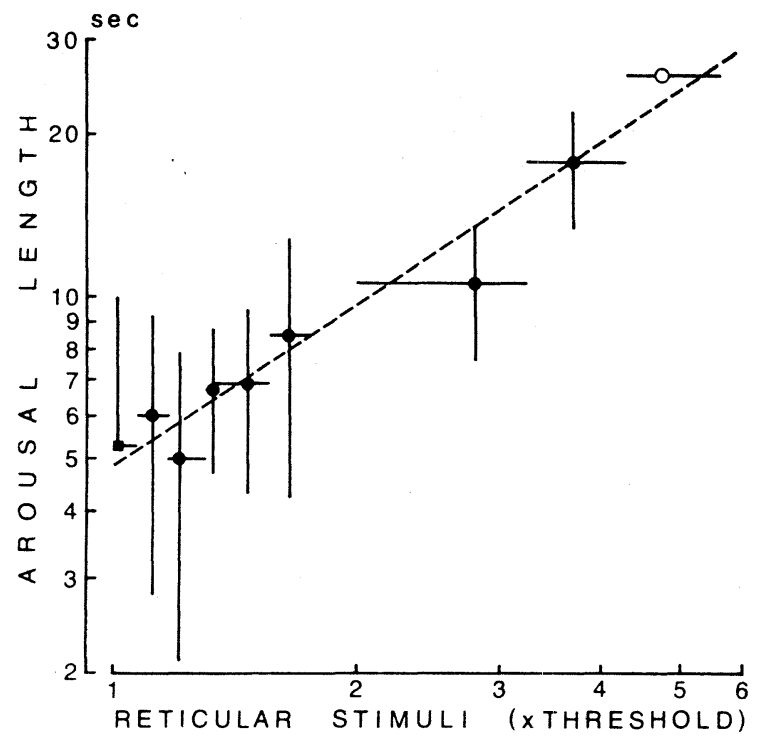

Fig. 7. Relationship between $\mathrm{AL}$ and intensity of reticular stimuli. Both variables are plotted in logarithmic scales. Each point is obtained as the mean of both variables in 10 trials. Vertical bars indicate standard deviations, and horizontal bars show ranges of stimulus intensity. An open circle is obtained exceptionally from three trials. For one point of square, standard deviation in AL is illustrated only as positive. A broken straight line is drawn by eye as having an exponent of 1 .

intensity illustrated in Fig. 5. The response amplitudes measured in the three selected cells are again plotted in Fig. 8 as a function of AL, where the mean amplitudes are calculated for each AL. As is expected, the amplitude of DF responses maintains an approximately constant value or is reduced, whereas $\mathrm{E}$ responses increase as AL becomes prolonged.

These characteristic relations could be generalized to the total population of cells by extending examination to the response incidence. As plotted in Fig. 9 with circles for all 117 reticular trials ( $c f$. Table 1), DF and $\mathrm{E}$ incidences show their dependence on AL in a manner similar to the stimulus-response relationships of Fig. 8. The same plotting is also made for all 330 episodes of natural EEG arousal ( $c f$. Table 1) with squares in Fig. 9. E incidences gradually increase for a longer AL in both the reticular (open circles) and natural trials (open squares). DF incidences decrease for ALs in the longest range with the degree being greater in the reticular (closed circles) than in the natural trials (closed squares). This difference in DF incidences is due to the masking of DF by $\mathrm{E}$ responses (Fig. 4C) which is seen more frequently for reticular than natural trials.

EEG stage shift. As another intensity parameter we adopted the extent in shift of EEG stages from synchronization to desynchronization. Conventionally, four stages were classified as illustrated in Fig. 10A: 1) highly synchronized with 


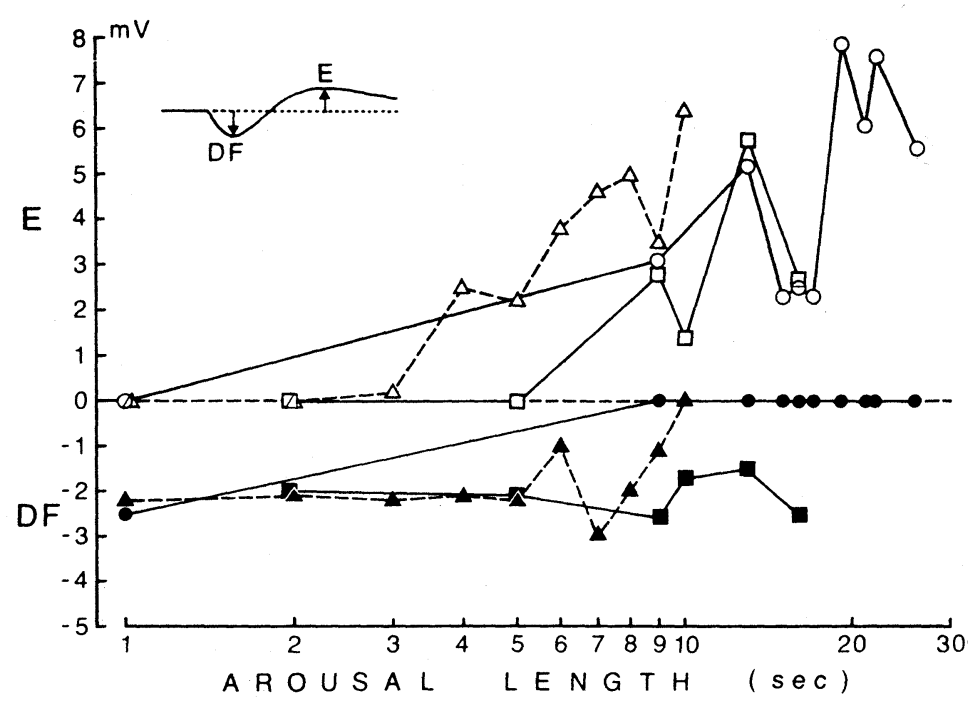

Fig. 8. Relationships between DF or $\mathrm{E}$ responses and AL. Three cells illustrated in Fig. 5 are used with the same conventions.

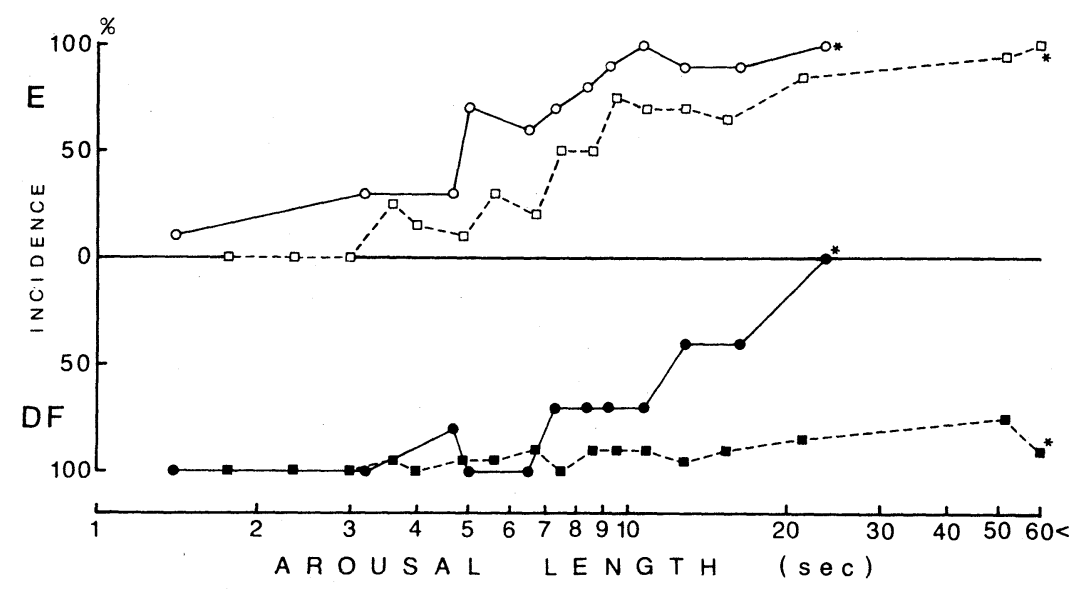

Fig. 9. Relationships between $\mathrm{DF}$ or $\mathrm{E}$ incidence and $\mathrm{AL}$. For 117 trials of reticular stimuli, each incidence in 10 trials is plotted with filled (DF) and open circles (E) as the function of mean $\mathrm{AL}$ of 10 trials, except in plottings with asterisks made from seven trials. For 330 natural episodes, the same variables in 20 trials, except those of 10 trials with asterisks, are plotted with filled and open squares.

large slow waves and spindle burst (S stage), 2) moderately synchronized with a mixture of slow and fast activities $\left(S_{d}\right.$ stage $), 3$ ) moderately desynchronized with contamination of small slow waves $\left(D_{s}\right.$ stage) and 4 ) highly desynchronized with continuing low voltage fast activity (D stage). These stages were common in 
the motor and visual EEG, except that the spindle burst was abortive or occurred less frequently in the latter.

The stage shift was categorized into six, as illustrated in Fig. 10A with numbering. The extent of stage shift was presumed to be large for No. 6, moderate for Nos. 4 and 5, and small for Nos. 1, 2, and 3. This presumption was verified in the relationship between DF or E incidence and the stage shift. Each column in Fig. 10B represents DF and $\mathrm{E}$ incidences in percent in the total trials with each stage shift in the motor EEG. Different patterns of columns indicate different extents of stage shift. For example, $\mathrm{E}$ incidence is 0 in 4 trials that show shift No. $1,31 \%$ of 19 trials with shift No. 2 and so on, revealing a tendency to increase in $\mathrm{E}$ responses as the shift becomes large. DF incidence is near $100 \%$ for the weak EEG arousal of shift Nos. 1, 2, and 3, and shows a tendency to small decrease for greater stage shifts.

In the 140 selected trials, DF and E incidences were similarly related to the stage shift in the visual EEG. In some of these trials the visual EEG showed no stage shift from either $S, S_{d}$ or $D_{s}$ stage. These cases were counted as Nos. 7, 8 , and 9, respectively, to be the weakest arousal because the stage shift occurred only in the motor EEG. Figure 10C illustrates patterns of increasing E incidence and of little change in DF incidence towards extensive stage shift in these 140 trials.

The relationships illustrated in Fig. 10B and C thus indicate similar patterns

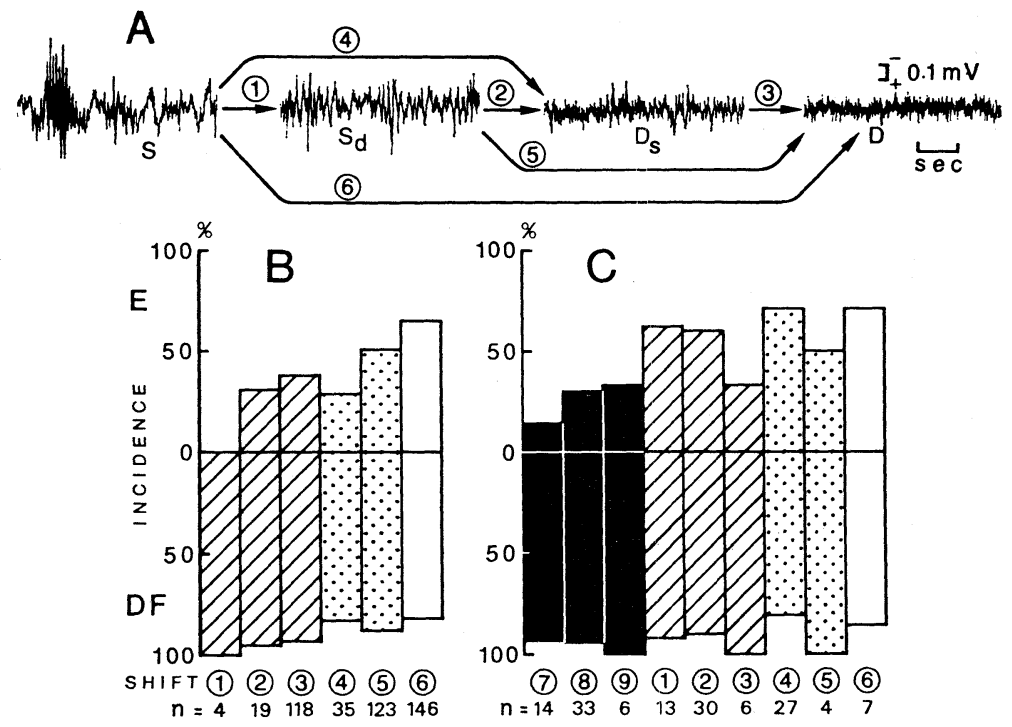

Fig. 10. Four EEG stages (A) and response incidences versus EEG stage shift relationships (B, C). Records in A are taken from the motor cortex. Stage shifts are numbered as in A, and ordered by their extent on the abscissae in B for motor EEG and in C for visual EEG. For each shift, sampled number $(n)$ of EEG arousal is indicated at the bottom of figures in $\mathrm{B}$ and $\mathrm{C}$. 
to the stimulus-response relationships so far demonstrated in Figs. 5, 6, 8, and 9.

\section{Excitatory tonus in different EEG stages}

Long-lasting intracellular recordings have provided the relationship of the $\mathrm{E}$ or DF incidence to the EEG stage shift with an underlying cellular mechanism. For example, responses of a DF cell were recorded in the condition of well-maintained resting potentials during a total of 47 episodes of EEG arousal with the stage shifts Nos. 3, 5, and 6, as illustrated in Fig. 11A with specimen records. Of these trials in which the final arousal reached stage D, 11 showed a stage shift from $S$ (No. 6), 20 from $S_{d}$ (No. 5) and 16 from $D_{s}$ (No. 3). Mean resting levels of the membrane potential were measured in each trial for three periods during the control EEG and during the maximal DF and E responses. These values were averaged for each group of stage shifts. The mean potentials thus obtained are plotted with different symbols in Fig. 11B with standard deviations as vertical bars. During the three control EEG stages, $D_{s}, S_{d}$ and $S$, the potential levels indicated with dotted, broken and solid lines differ by a few millivolts. However, all the DF and $E$ responses reach similar levels of peaks during stage D arousal, regardless of the difference in control level. Thus, when the control membrane potential is at a most hyperpolarized level (No. 6, stage S), DF response is little and $\mathrm{E}$ response becomes most prominent. When the membrane is most depolarized during the control period (No. 3, stage $\mathrm{D}_{\mathrm{s}}$ ), DF becomes prominent with little $E$ response. From stage $S_{d}$ (No. 5) DF and $E$ responses develop with amplitudes in between. It can be said that the control potential level determines the amplitudes of DF and $\mathrm{E}$ responses in a reciprocal manner between each other.

Analyses illustrated in Fig. 11A and B suggest that there is a tonic excitatory level according to each EEG stage, which may be termed an excitatory tonus after the concept of "cortical tonus" (BREMER, 1954, 1973). The excitatory tonus would be lowest during stage $\mathrm{S}$, and become higher in the order of stages $\mathrm{S}_{\mathrm{d}}, \mathrm{D}_{\mathrm{s}}$, and D.

To generalize this finding, a part of the data in Fig. 10B (Nos. 3, 5, 6) is reconstructed in Fig. 11C with the highest tonus (an uppermost horizontal broken line D) which is made coincident with the top of incidence columns in the respective stage shifts; $D_{s}, S_{d}$, and $S$ to $D$. If one measures the excitatory tonus in the DF cell as the level of boundaries between $\mathrm{E}$ (open columns) and DF incidence columns (hatched), Fig. 11C can be read as follows: the excitatory tonus increases in the order of $\mathrm{S}<\mathrm{S}_{\mathrm{d}}<\mathrm{D}_{\mathrm{s}}<\mathrm{D}$, as directed with a vertical arrow to the right in $\mathrm{C}$. E responses develop from an excitatory tonus level to the highest with an amplitude that increases according to the extent of stage shifts, and DF responses slightly decrease for larger stage shifts.

The analysis in this section suggests that an excitatory tonus exists in the group of DF cells throughout all the EEG stages including the tonic phase of EEG 

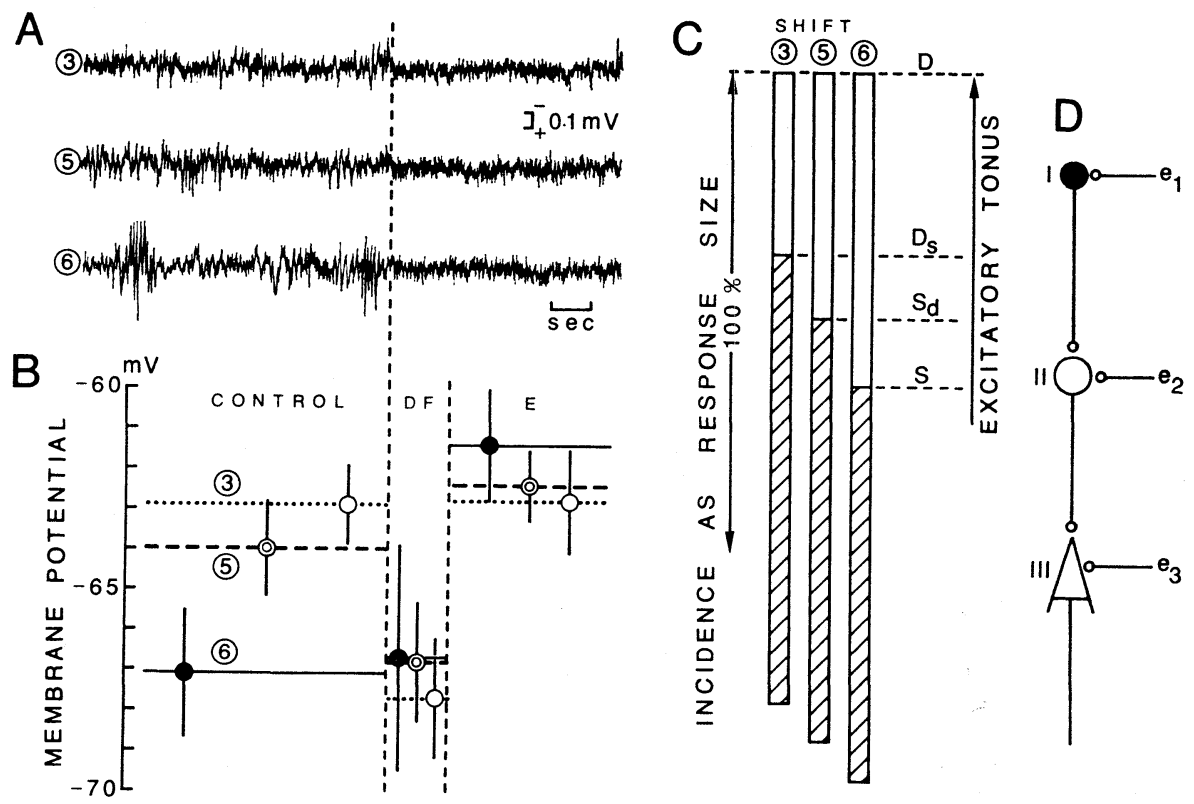

Fig. 11. Four EEG stages and corresponding membrane potential levels as excitatory tonus. A shows EEG arousal of three types of stage shift in motor cortex. In B, mean membrane potentials and standard deviations during control and aroused EEG in stages $\mathrm{D}, \mathrm{D}_{\mathrm{s}}, \mathrm{S}_{\mathrm{d}}$, and $\mathrm{S}$ were calculated in a fast PT cell (latency from cerebral peduncle, 0.8 msec; depth, $1,020 \mu \mathrm{m}$ ) with 47 selected episodes of EEG arousal. These membrane potentials are shown in a voltage scale with different symbols and horizontal lines according to periods of control, DF and $\mathrm{E}$ fractionized by two vertical broken lines. In C, response incidence columns with a scale of $100 \%$ used in Fig. 10B are re-arranged as response sizes and levels of assumed excitatory tonus. D, a three-neurone (I, II, III) relay with excitatory inputs $\left(\mathrm{e}_{1}, \mathrm{e}_{2}, \mathrm{e}_{3}\right)$ assumed to explain mechanisms of generating $\mathrm{DF}+\mathrm{E}$ response pattern. Excitatory or inhibitory nature of neurones and their axon terminals is indicated with open or filled symbols, respectively. See text for further explanation.

arousal, and that this tonus is depressed transiently during phasic EEG arousal.

\section{Other indices of arousal intensity}

In an attempt to obtain reliable measures of arousal intensity it was reasonable to adopt the hippocampal activity ( $c f$. LINDSLEY and WILSON, 1975; BERRY and THOMPSON, 1978). The demonstration of changes in the hippocampal RSA and its IF in Fig. 3 was suggestive.

However, the changes in the hippocampal RSA were somehow dependent on the experimental conditions. RSA did not develop in a few cases during EEG arousal. In some cases the EEG desynchronization on arousal accompanied appearance of the hippocampal RSA. On the other hand, in some other cases 
RSA that had existed during the control period was suppressed on EEG arousal. In the last cases the suppression of RSA often corresponded with the initial DF response, and a following phase of exaggerated RSA corresponded with the late E response. The factors controlling these different patterns of hippocampal RSA were not examined systematically at the present stage of our research. Therefore, we have used the hippocampal activity only as a feeble but useful index of arousal in this and the following papers without attempting to quantify (EzURE and OSHIMA, 1981a, b).

\section{DISCUSSION}

Characteristic relationships have now been established between the physiological intensity of EEG arousal and the intracellular responses of DF cells. The physiological intensity of EEG arousal could be defined in terms of both the external stimuli and the response patterns of EEG. The intimate relationship between the effect of external stimuli and the EEG patterns has agreed well with experience in the chronic experiment on mammalian animals or man, in that the effect of physical stimuli in arousing animals or inducing the EEG desynchronization depends on the stage of sleep or the degree of EEG synchronization during the control period before stimulation. It entails that even the spontaneously occurring EEG arousal with indications of the highest intensity should have been induced by the most intense stimuli, although these stimuli were neither qualified nor quantified.

The intracellular responses could be related to the intensity parameters adopted in this study. As the EEG arousal became intense, DF responses were unaltered or decreased, and $\mathrm{E}$ responses were increased. This reciprocal relation between the two responses will be discussed below from the aspects of neuronal mechanisms and of functional implications.

Neuronal mechanisms. Reciprocity of DF and E responses in terms of both the relationships of arousal intensity versus response (Figs. 5-10) and excitatory tonus versus response (Fig. 11A, B) suggests a common neuronal mechanism underlying the generation of these two responses. By nature, these responses are the changes in membrane potential maintained by excitatory bombardment onto DF cells.

Earlier findings of DF and E responses in fast PT cells had already involved the reciprocal fashion of their occurrence. Thus, DF and $\mathrm{E}$ responses were found separately by two groups of investigators in observations during reticular stimulation (KLeE et al., 1964; Акімото and SAIto, 1966; KleE, 1966). As was suggested in a previous paper (INUBUSHI et al., 1978a), this discrepancy has now been explicable by different intensities of EEG arousal. In the present study we could observe the exclusive $\mathrm{E}$ response during both the natural and reticularinduced EEG arousal and relate its occurrence to the arousal intensity. The ex- 
clusive $\mathrm{E}$ response was more easily elicited by the reticular than natural stimuli (Fig. 9), or by the EEG stage shift from more synchronized pattern (Fig. 11A, B). It has become clear that the earlier investigators observed the exclusive DF and $\mathrm{E}$ responses as the two possible extremes.

A neuronal device to generate DF responses was previously postulated as a three-neurone relay through which a downward cascade transmission resulted in these responses of deep pyramidal cells (INUBUSH et al., 1978b). As illustrated in Fig. 11D, an excitatory input $\left(\mathrm{e}_{1}\right)$ to an uppermost inhibitory neurone (I) causes DF responses in a deep cell (III) via the relay of a middle layer excitatory cell (II). Keeping this neuronal relay on, E responses in the deep cell (III) could be induced theoretically either by other excitatory inputs $\mathrm{e}_{2}$ or $\mathrm{e}_{3}$ or both. In a previous paper (INUBUSH et al., 1978b) the input $\mathrm{e}_{3}$ was postulated to occur either through the constituents of the intracortical reverberating circuit such as the collateral excitatory relays or by the excitatory influence from the subcortical structures, particularly from the thalamus. The present study would propose the other route formed by the input $\mathrm{e}_{2}$ and a middle layer cell (II) as an additional candidate in yielding E responses of the deep cell (III). From the analysis illustrated in Fig. 11A and $\mathrm{B}$, it is postulated that the middle layer cell (II) plays a role maintaining the excitatory tonus in its target deep cell (III), thus controlling the amplitudes of DF and E responses in a reciprocal fashion according to the control EEG stage (A). Since the late $\mathrm{E}$ response is characterized with its tonic maintenance of the membrane potential (Fig. 1), the factor of the excitatory tonus may be an essential part of this response.

This additional mechanism of generating the late $\mathrm{E}$ response requires the middle layer cell (II) which would respond with an initial inhibition and a late excitation during the intense EEG arousal. Evidence for the existence of cells of this type will be given in a following paper (EzURE and OsHIMA, 1981b).

Functional implications. The initial DF response has been discussed as the neuronal reset for excitation which may correspond with an initial stage of the orienting response (INUBUSH et al., 1978b). This interpretation fits well the arousal intensity-response relationships obtained in the present study. DF responses are produced in full by the threshold stimulus or to the weakest EEG arousal, and never grow up in response to intensified stimuli or arousal. It is suggested that DF responses are a biologically passive process or a general set on receipt of a "novelty" factor of stimuli.

On the other hand, E responses showed increases in parallel with the intensity of external stimuli or EEG arousal. They would represent an active process of encoding an "intensity" factor of stimuli, and thus correspond to the state of an animal's positively exploring the environment.

As a main group of output neurones, the deep layer DF cells including fast PT cells should represent most faithfully the cerebral state during phasic and tonic EEG arousal, as discussed above. The functional significance of the initial DF 
response could be fully understood as the result of integrative actions of all cortical neurones including the neurone-relay illustrated in Fig. 11D (INUBUSHI et al., 1978b). However, in order to understand the functional significance of the late $\mathrm{E}$ response, one should further ask how the excitation of DF cells is brought about, and how the excited DF cells exert their influences on other neurones. Analyses for this purpose will be made extensively in the following two papers (EzURE and OsHima, 1981a, b).

The authors thank Prof. Shizuo Torii of Toho University for his kind guidance in preparing the midpontine pretrigeminal cats in the early stage of the present work. Thanks are also due to Miss Takako Sato for technical assistance. The work was partly supported by a Grant-inAid for Scientific Research from the Ministry of Education, Science and Culture of Japan.

\section{REFERENCES}

Акімото, Н. and SaIto, Y. (1966) Synchronizing and desynchronizing influences and their interactions on cortical and thalamic neurons. In: Progress in Brain Research, ed. by Tokizane, T. and Schadé, J. P. Elsevier, Amsterdam, Vol. 21A, Part A, pp. 323-351.

Allison, T. and Goff, G. D. (1968) Potentials evoked in somatosensory cortex to thalamocortical radiation stimulation during waking, sleep, and arousal from sleep. Arch. Ital. Biol., 106: $41-60$.

Berry, S. D. and Thompson, R. F. (1978) Prediction of learning rate from the hippocampal electro-encephalogram. Science, 200: 1298-1300.

BRemer, F. (1954) The neurophysiological problem of sleep. In: Brain Mechanisms and Consciousness, ed. by Adrian, E. D., Bremer, F., and Jasper, H. H. Blackwell, Oxford, pp. 137-162.

BREMER, F. (1973) Tonus cortical et afférences cérébrales. Arch. Ital. Biol., 111: 462-467.

Courtois, A. and CordeAu, J. P. (1969) Changes in cortical responsiveness during transition from sleep to wakefulness. Brain Res., 14: 199-214.

Ezure, K., InUbushi, S., Kobayashi, T., Oshima, T., and ToriI, S. (1980) Mixed type responses on EEG arousal in cat motor cortical neurons. In: Integrative Control Functions of the Brain, ed. by Iто, M. Kodansha Scientific, Tokyo and Elsevier, Amsterdam, Vol. 3, pp. 140141.

Ezure, K. and Oshima, T. (1981a) Excitation of slow pyramidal tract cells and their family neurones during phasic and tonic phases of EEG arousal. Jpn. J. Physiol., 31:737-748.

Ezure, K. and Oshima, T. (1981b) The structure of EEG arousal as a dynamic ensemble of neuronal activities in cat motor cortex. Jpn. J. Physiol., in press.

FANGel, C. and KAADA, B. R. (1960) Behavior "attention" and fear induced by cortical stimulation in the cat. Electroencephalogr. Clin. Neurophysiol., 12: 575-588.

FloRU, R. (1975) Psychophysiological investigations on attention. In: Neuronal Mechanisms of the Orienting Reflex, ed. by Sokolov, E. N. and Vinogradova, O. S. Lawrence Erlbaum Associated, Inc., Hillsdale, New Jersey, pp. 239-251.

INUBushi, S., KobaYASHI, T., Oshima, T., and ToRII, S. (1978a) Intracellular recordings from the motor cortex during EEG arousal in unanaesthetized brain preparations of the cat. $J_{p n} . J$. Physiol., 28: 669-688.

INUbushi, S., KobaYashi, T., Oshima, T., and ToRII, S. (1978b) An intracellular analysis of EEG arousal in cat motor cortex. Jpn. J. Physiol., 28: 689-708.

KLEE, M. R. (1966) Different effects on the membrane potential of motor cortex units after

Vol. 31, No. 5, 1981 
thalamic and reticular stimulation. In: The Thalamus, ed. by PUrPura, D. P. and YAHr, M. D. Columbia Univ. Press, New York, pp. 287-322.

KLeE, M. R., LuX, H. D., and OfFenLOCH, K. (1964) Veränderungen der Membranpolarization und der Erregbarkeit von Zellen der motorischen Rinde während hochfrequenter Reizung der Formatio reticularis. Arch. Psychiatr. Nervenkr., 205: 237-261.

LINDSLEY, D. B. and Wilson, C. L. (1975) Brainstem-hypothalamic systems influencing hippocampal activity and behaviour. In: The Hippocampus, Vol. 2. Neurophysiology and Behaviour, ed. by IsaAcson, R. L. and Pribram, K. H. Plenum Press, New York, pp. 247278.

Oshima, T. (1969) Studies in pyramidal tract cells. In: Basic Mechanisms of the Epilepsies, ed. by JASPER, H. H., WARD, A. A., and Pope, A. Little, Brown and Co., Boston, pp. 253-261.

Pavlov, I. P. (1927) Conditioned Reflexes. An Investigation of the Physiological Activity of the Cerebral Cortex (Translated by Anrep, G. V.), Dover Publ., Inc., New York, pp. 12, $29,112$.

SHARPLESS, S. and JASPER, H. (1956) Habituation of the arousal reaction. Brain, 79: 655-681.

Sokolov, E. N. (1963) Higher nervous functions: The orienting reflex. Annu. Rev. Physiol., 25: $545-580$.

STERIADE, M. (1970) Ascending control of thalamic and cortical responsiveness. In: International Review of Neurobiology, ed. by Pfeiffer, C. C. and Smythies, J. R. Academic Press, New York, Vol. 12, pp. 87-144.

Steriade, M., Deschênes, M., and OAKson, G. (1974a) Inhibitory processes and interneuronal apparatus in motor cortex during sleep and waking. I. Background firing and responsiveness of pyramidal tract neurons and interneurons. J. Neurophysiol., 37: 1065-1092.

Steriade, M., DeschêNes, M., Wyzinski, P., and Hallé, J. Y. (1974b) Input-output organization of the motor cortex and its alterations during sleep and waking. In: Basic Sleep Mechanisms, ed. by Petre-Quadens, O. and Schlag, J. Academic Press, New York, pp. 143-200.

Steriade, M. and Hobson, J. A. (1976) Neuronal activity during the sleep-waking cycle. Prog. Neurobiol., 6: 155-376.

WALSH, J. T. and CORDEAU, J. P. (1965) Responsiveness in the visual system during various phases of sleep and waking. Exp. Neurol., 11: 80-103. 